\title{
Important relation between self- efficacy, sense of coherence, illness perceptions, depression and anxiety in patients with inflammatory bowel disease
}

\author{
Adi Eindor- Abarbanel (D) ,' Timna Naftali, ${ }^{2}$ Nahum Ruhimovich, ${ }^{2}$ \\ Ariella Bar-Gil Shitrit, ${ }^{3}$ Fabiana Sklerovsky-Benjaminov, ${ }^{2}$ Fred Konikoff, ${ }^{2}$ \\ Shay Matalon, ${ }^{1}$ Haim Shirin, ${ }^{1}$ Yael Milgrom, ${ }^{3}$ Tomer Ziv-Baran, ${ }^{4}$ \\ Efrat Broide $^{1}$
}

- Additional material is published online only. To view please visit the journal online (http://dx.doi.org/10.1136/ flgastro-2020-101412)

For numbered affiliations see end of article.

\section{Correspondence to}

Dr Adi Eindor- Abarbanel, Asaf Harofe Hospital, Zerifin 70300, Israel; adiabarbanel@gmail.com

AE-A and TN are joint first authors.

Received 13 January 2020

Revised 3 June 2020

Accepted 19 July 2020

Published Online First

25 August 2020

\section{Check for updates}

(C) Author(s) (or their employer(s)) 2021. No commercial re-use. See rights and permissions. Published by BMJ.

To cite: Eindor- Abarbanel A, Naftali T, Ruhimovich N, et al. Frontline Gastroenterology 2021;12:601-607.

\section{ABSTRACT}

Introduction Anxiety and depression are common disturbances in patients with inflammatory bowel diseases (IBD), and were found to impact the disease course. Illness perceptions (IPs), self-efficacy (SE) and sense of coherence (SOC) are important psychological functions, used by the individual to cope with his chronic disease.

Aims to investigate the association of IP, SE and SOC on anxiety and depression among patients with IBD.

Patients and methods Patients filled questionnaires including: demographic, socioeconomic and clinical features. Depression and anxiety were assessed using the Hospital Anxiety and Depression Scale. IP, SE and SOC were assessed using the Brief Illness perception Questionnaire, IBD-SE and SOC scales.

Results The study sample consisted of 299 patients with IBD, median age 34.15, 63\% females, $70.9 \%$ had Crohn's disease, filled the questionnaires. In the multivariate analysis, lower results in IP, SE and SOC were found to be associated with significantly increase anxiety (OR 8.35, p<0.001; OR 4.18, p=0.001; OR $4.67, p<0.001$, respectively) and depression (OR 15.8, $p=0.001$; OR 10.99, $p=0.029$; OR 6.12, $\mathrm{p}=0.014$

Conclusions Anxiety and depression are associated with IP, SE and SOC in patients with IBD. Clinicians should be aware of this impact, recognise their patients' psychological abilities to cope with the disease and improve those abilities, when needed, in order to achieve a better coping with the disease and to prevent the development of anxiety and depression.

\section{Significance of this study}

What is already known on this topic

- Anxiety and depression are common disturbances in patients with inflammatory bowel diseases (IBD).

- Illness perceptions (IP), self-efficacy (SE) and sense of coherence (SOC) are important psychological functions, that are used by the individual to cope with his chronic disease.

- IP and SOC influence anxiety and depression in patients with IBD.

What this study adds

- This is the first study to address the association between psychological aspects: IP, SOC and SE with anxiety and depression among patients with IBD.

- The results suggest a strong correlation between IP, SOC and SE and the development of emotional distress in patients with IBD.

How might it impact on clinical practice in the foreseeable future

- Early evaluation of IP, SOC and IBD-SE among patients with IBD, and adequate interventions, might prevent the development of anxiety and depression, and needs further research.

\section{INTRODUCTION}

Anxiety and depression are more prevalent among patients with inflammatory bowel diseases (IBD) than in the general population, especially during active disease. ${ }^{1-3}$ Patients with IBD found to have 
more psychiatric distress compared to patients with other gastrointestinal disorders, such as irritable bowel syndrome and colorectal cancer. ${ }^{4-6}$ There is evidence that anxiety and depression in patients with IBD may be associated with higher rate of disease relapse. ${ }^{7}$

The burden of chronic disease with a relapsing unpredictable course contributes to psychological distress in patients with IBD which interferes with patient's everyday life, and increases the emotional distress. ${ }^{8}$

Disease course and severity are related to development of anxiety and depression. ${ }^{9}$ However, individual differences including psychological adjustment to illness and coping strategies, can influence psychological distress thus leading to worsening disease course. ${ }^{10}$

Illness perception (IP) is an individual's mental representation of a disease. ${ }^{11}$ It is a mediator of illness symptoms and psychological distress. Studies investigating the relationship between IP, anxiety and depression in patients with IBD found a correlation between strong emotional response to the illness and psychological distress. ${ }^{1012}$ Studies also reported that after adjusting for disease severity, type of disease and gender, IP still has a significant influence on anxiety and depression. ${ }^{10}{ }^{11}$ However, the relationship between IP and other psychological functions has not been fully investigated among patients with IBD.

Sense of coherence (SOC) is a theoretical construct developed to explain why some people, regardless of stressful events, fall ill and others do not. This concept was introduced by Antonovsky, ${ }^{13}$ a medical sociologist. He formulated the theory of salutogenesis which focuses on personal resources needed to maintain health. SOC is considered to be influenced by comprehensibility, manageability and meaningfulness. ${ }^{14}$ Comprehensibility means that the individual considers structured, environmental demands. Manageability refers to the resources that an individual has to meet these demands. Meaningfulness is the understanding that these demands are worth the resources invested to deal with them. Therefore, SOC is considered a key tool in enabling a person to deal with a stressor. SOC was also found to be a good predictor of psychological distress among patients with IBD. Feritas et al ${ }^{15}$ found that in patients with IBD lower SOC was independently associated with higher levels of depression and anxiety.

Self-efficacy (SE) is the belief that an individual can carry out a task necessary to achieve a desired outcome. It strongly predicts health promoting behaviour in chronically ill patients, regardless of disease severity. ${ }^{16}$ $\mathrm{SE}$ is considered non-transferable from other life domains. An individual could have high SE in some assignments, but low SE when facing other situations. For this reason, Keefer $e t a l^{17}$ validated an IBD-SE scale that is directly related to the unique self-management requirements of the disease. Another study ${ }^{18}$ investigated the association between SE and depression in patients with heart failure and reported the effects of social support and depression on treatment adherence. To our knowledge, no studies have explored the association of SE with anxiety and depression in patients with IBD.

As IP, SOC and SE were found to be important predictors of an individual's ability to cope with chronic disease we aimed to investigated their possible effects on anxiety and depression among patients with IBD.

\section{METHODS \\ Participants}

Between November 2015 and May 2017, adult (age $\geq 18$ ), consecutive ambulatory patients with an established diagnosis of IBD were enrolled in the study. Diagnosis of Crohn's disease (CD) and ulcerative colitis (UC) were previously confirmed by established criteria based on clinical, endoscopic, histopathological and radiological findings. Patients were recruited from three university hospital-affiliated hospitals in Israel: Assaf Harofeh, Meir Medical Center and Shaare Zedek Medical Center.

All patients completed questionnaires that included demographic data, disease parameters and psychological profile, as described below.

\section{Demographic and disease characteristics}

Demographic characteristics included age, gender, relationship status (categorised as: in a relationship, single or past relationship), level of income (categorised as low, medium or high), working hours per week and religious belief (secular, orthodox or ultra orthodox). Clinical risk factors included type and duration and severity of disease, and number of concomitant medications for the treatment of other diseases (under 3 or $\geq 3$ ).

Clinical disease severity was calculated based on a scale modified from a study by the Groupe d'Etudes Thérapeutiques des affections Inflammatoires Du tube Digestif ${ }^{19}$ group. The severity score was calculated based on an average of disease severity as reported by the physician. The score was graded on a scale from 0-5 (0-no symptoms, 1-mild symptoms; 2-medium symptoms; 3 -active disease; 4-hospitalisation in the past year; 5 -surgery in the past year or current stoma). Another component of severity was based on medical treatment, summing up a scale varying from 0 to 5 ( 0 -no treatment, 1-5-aminocalicylic acid (ASA) or antibiotics, 2-less than $10 \mathrm{mg}$ per day dose steroids, 3-steroids in a regular dose, 4-immunomodulatory treatment, 5 -biological treatment). These scales were calculated for each year of the last 3 years. The final score was the average of the score from each year over the last 3 years (see online supplementary file). 


\section{Psychological factors}

Measures of psychological factors

IPs were assessed by the Brief Illness Perception Questionnaire (BIPQ). ${ }^{20}$ This 9-item questionnaire explores the cognitive and emotional representations of illness across eight dimensions: Consequences, Timeline, Personal Control, Treatment Control, Identity, Concerns, Understanding and Emotional Response. Items were assessed on 11-point Likert scale (0-not affecting my life at all to 10 -severely affecting my life). SE was evaluated using the IBD-Self Efficacy scale. ${ }^{11821}$ This 29-item scale was developed by Keefer et $a l,{ }^{17}$ based on patient interviews, validated SE measures for other diseases and SE theory. The instrument assesses the level of confidence in managing various disease-related tasks. Item scores range from 1 to 10 (1-not at all to 10-totally). Higher scores reflect greater disease self-management efficacy. Items were grouped conceptually into four subscales: managing stress and emotions, managing medical care, managing symptoms and disease and maintaining remission. SOC was assessed according to the SOC orientation to life score. ${ }^{22}$ The SOC-13 scale measures the degree to which an individual views the world as comprehensible (five items), manageable (four items) and meaningful (four items), using a 7-point Likert scale. The total SOC-13 score is the sum of the items, ranging from 13 to 91, with higher scores reflecting better SOC. The author granted permission to use this scale.

\section{Measure of anxiety and depression}

Anxiety and depression were assessed using the Hospital Anxiety and Depression Scale (HADS). ${ }^{23}$ This is a 14-item scale assessing anxiety (seven items) and depression (seven items) in patients with organic pathology. A higher score corresponds to higher severity of emotional stress. We used acut-off score of above 10 as a marker for anxiety or depression. ${ }^{24} 25$

\section{Statistical analysis}

Categorical variables were described using frequency and percentage. Continuous variables were evaluated for normal distribution using histograms and Q-Q plots. Normally distributed, continuous variables were described as mean and SD and non-normally distributed variables were expressed as median and interquartile range. Independent sample T-test and MannWhitney test were used to compare continuous variables between categories. Categorical variables were compared using chi- square test or Fisher's exact test. Correlation between continuous variables was evaluated using Spearman's rank correlation coefficient test.

The continuous psychological factors were divided into two categories, using the median as the threshold value. Multivariate analyses were performed using logistic regression. The logistic regression included two blocks. Age, gender, type and severity of disease were forced into the first block. The second block included marital status, working hours, religious belief, severity of disease, the need to take more than three medications, level of income and duration of disease. The variables were selected using the backward step-wise (likelihood ratio) method. The variables in the second block were those associated with the outcome, at the significance level of $\mathrm{p}<0.1$. Each psychological parameter was tested separately with the variables above, in order to avoid intercorrelation. All statistical tests were two-tailed. $\mathrm{P}<0.05$ was considered statistically significant. In the multivariate analyses, the continuous outcomes were divided into two categories using the median as the threshold value. The direction of the test results was changed so the OR reflects the odds of getting the 'less favourable' test result. All statistical analyses were performed using IBM SPSS Statistics for Windows, V.23.0 (Released 2015, IBM).

\section{RESULTS}

\section{Patient population}

From November 2015 through May 2017, we interviewed 299 consecutive patients with IBD attending outpatient clinics in the participating hospitals. Their median age was 34.15 (IQR 27.44-44.83) years, 110 (36.8\%) were men and 189 (63.2\%) women. Diagnosis of CD was established in $212(70.9 \%)$ patients, UC in 77 (25.8\%) and Inflammatory Bowel Disease- Unclassified (IBD-U) in 10 (3.3\%). The median duration of disease was 9.76 years (IQR 5-16.01).

All participants completed the HADS score. Depression, according to the score, was documented in 28 $(9.36 \%)$ patients, and anxiety was documented in 70 (23.41\%). Demographic and disease characteristics comparing patients with or without anxiety and/or depression are listed in table 1 . No significant difference was found between patients with or without anxiety. However, we found that depression was more prevalent among older patients (43.36 (IQR 33.0257.85), 33.59 (IQR 27.35-44.14), p=0.006, respectively). Depression was more common among patients with CD compared to UC $(p=0.036)$. Although employment status was similar between depressed and non-depressed patients, depressed patients worked fewer hours per week (22 (IQR 0-36.25) 37 (IQR 4.5-45), $\mathrm{p}=0.021)$.

\section{Psychological profile}

The median results of the BIPQ, IBD-SE and SOC-IBD scores are presented in table 2. Mean SOC score was $61.5 \pm 11.34$ maximum possible score 91). Median total BIPQ score was 45 IQR 36-52.5 (maximum possible score 80 ). Individual parameters of the BIPQ scale are listed in table 2. Median SE score was 224 IQR188-251(maximum possible score 290).

In the multivariate analysis, anxious and depressed patients had significantly more negative IP in the categories of consequences, identity, personal control and emotional response (tables 3 and 4). 
Table 1 Demographic and disease characteristics of patients with anxiety and depression

\begin{tabular}{|c|c|c|c|c|c|c|}
\hline \multirow[b]{2}{*}{ Characteristic } & \multicolumn{3}{|l|}{ Anxiety } & \multicolumn{3}{|l|}{ Depression } \\
\hline & Yes $(n=70)$ & No $(n=229)$ & P value & Yes $(n=28)$ & No $(n=271)$ & $P$ value \\
\hline Age median (IQR) & $37.6(28.5-49.33)$ & $33.6(27.43-44.49)$ & 0.243 & $43.36(33.02-57.85)$ & $33.59(27.35-44.14)$ & 0.006 \\
\hline Gender n (\%) & & & 0.288 & & & 0.484 \\
\hline Male & $22(20)$ & $88(80)$ & & $12(10.9)$ & $98(89.1)$ & \\
\hline Female & $48(25.4)$ & $141(74.6)$ & & $16(8.5)$ & $173(91.5)$ & \\
\hline Employed, n (\%) & $51(23)$ & $171(77)$ & 1 & $17(7.7)$ & $205(92.3)$ & 0.13 \\
\hline Hours worked, median (IQR) & $31(0-45)$ & $36(0-45)$ & 0.437 & $22(0-36.25)$ & $37(4.5-45)$ & 0.021 \\
\hline Marital status, n (\%) & & & 0.196 & & & 0.157 \\
\hline Single & $14(17.3)$ & $67(82.7)$ & & $5(6.2)$ & $76(93.8)$ & \\
\hline In a relationship & $47(24.1)$ & $148(75.9)$ & & $18(9.2)$ & $177(90.8)$ & \\
\hline Past relationship & $7(35)$ & $13(65)$ & & $4(20)$ & $16(80)$ & \\
\hline Education > 12 years, $n(\%)$ & $33(19.4)$ & $137(80.6)$ & 0.091 & $13(7.6)$ & $257(92.4)$ & 0.306 \\
\hline Disease duration, median (IQR) & $10(5-17.01)$ & $9.13(5-15.86)$ & 0.462 & $9.5(4.25-22.26)$ & $9.76(5-15.43)$ & 0.469 \\
\hline Type, n (\%) & & & 0.127 & & & 0.036 \\
\hline Crohn's & $47(22.2)$ & $165(77.8)$ & & $21(9.9)$ & $191(90.1)$ & \\
\hline UC & $18(23.4)$ & $59(76.6)$ & & $4(5.2)$ & $73(94.8)$ & \\
\hline IBD-U & $5(50)$ & $5(50)$ & & $3(30)$ & $7(70)$ & \\
\hline Severity, median (IQR) & $6(3.66-7.16)$ & $6(3.66-8)$ & 0.939 & $6.49(5.41-8.08)$ & $6(3.66-8)$ & 0.228 \\
\hline
\end{tabular}

UC, ulcerative colitis.

Furthermore, anxious patients had lower median SOC score (OR 4.67, 95\% CI 2.08 to $10.5, \mathrm{p}<0.001$ ) and lower median SE score (OR 4.18, 95\% CI 1.82 to 9.64, $\mathrm{p}=0.001)$.

Depressed patients had lower median SOC score (OR 6.12, 95\% CI 1.41 to $25.79, \mathrm{p}=0.014$ ) and lower SE median score (OR 10.99, 95\% CI 1.28 to 94.09 , $\mathrm{p}=0.029$ ).

\begin{tabular}{lc}
\hline Table 2 & Results of the psychological questionnaires \\
\hline Characteristic & Patients (all) $n=299$ \\
\hline SOC IBD-orientation mean (SD) & $61.5(11.34)$ \\
\hline BIPQ median (IQR) & $7(5-9)$ \\
\hline Consequences & $10(9-10)$ \\
\hline Timeline & $6(4-8)$ \\
\hline Personal control & $8(6-9)$ \\
\hline Treatment control & $7(4-8)$ \\
\hline Identity & $7(5-9)$ \\
\hline Concerns & $8(6-9)$ \\
\hline Understanding & $7(3-8)$ \\
\hline Emotional response & $45(36-52.5)$ \\
\hline BIPQ total & \\
\hline IBD self-efficacy median (IQR) & $68(56-78.75)$ \\
\hline Management feeling & $77(70-80)$ \\
\hline Management medications & $45(33-56)$ \\
\hline Management symptoms & $37(29-43)$ \\
\hline Keeping remission & $224(188-251)$ \\
\hline Total IBD-SE &
\end{tabular}

BIPQ, Brief IIIness Perception Questionnaire; IBD-SE, Inflammatory Bowel Disease-Self Efficacy scale; SOC, sense of coherence.

\section{DISCUSSION}

Chronic diseases accompanied by pain, functional impairment and emotional dysfunction constitute a challenging problem for the individual. ${ }^{26}$ Patient harbour a complex of personality traits on which they can draw in order to cope with challenges arising from the disease. Only a few studies investigated psychological factors that influence coping strategies ${ }^{27}$ and their effect on emotional stress in patients with IBD. ${ }^{10} 1215$

This study was the first to investigate the influence of IBD-SE on psychological distress. We found that there is a significant correlation between lower IBD-SE and the development of anxiety and depression. In contrast to previous studies, we investigated the combination of three key functions: IP SE and SOC and found that these three functions were strongly correlated with anxiety and depression.

The results of this study agree with those of earlier studies that showed the strong influence of $\mathrm{IP}^{10}{ }^{11}$ and $S O^{15}$ on anxiety and depression among patients with IBD. Specific elements from the IP that were correlated with increased depression and anxiety included consequences, identity, personal control and emotional response. In other words, the way a patient perceives his disease and his ability to manage it will influence the possibility of development of anxiety and depression. A negative perception of the current situation will have profound implementation on the development of anxiety and depression.

Interest in how patients with chronic illness can manage their disease is growing. ${ }^{26}$ Although IP, SE and SOC are inherent components of every patient's beliefs and resources, some researchers investigated 
Table 3 Multivariate analysis of psychological parameters influencing anxiety

\begin{tabular}{|c|c|c|c|c|}
\hline Psychological factors & Adjusted* OR $(95 \% \mathrm{Cl})$ & $P$ value & Adjusted † OR $(95 \% \mathrm{CI})$ & $P$ value \\
\hline BIPQ total & 8.44 (3.87 to 18.41$)$ & $<0.001$ & 8.35 (3.68 to 18.98$)$ & $<0.001$ \\
\hline Consequences & 5.69 (2.82 to 11.47$)$ & $<0.001$ & 8.44 (3.78 to 18.87$)$ & $<0.001$ \\
\hline Personal control & 2.34 (1.23 to 4.4$)$ & 0.008 & $2.48(1.27$ to 4.83$)$ & 0.008 \\
\hline Treatment control & 1.34 (0.72 to 2.52$)$ & 0.36 & 1.32 (0.68 to 2.56$)$ & 0.415 \\
\hline Identity & $3.32(1.76$ to 6.24$)$ & $<0.001$ & 3.64 (1.87 to 7.08$)$ & $<0.001$ \\
\hline Concerns & 9.1 (4.37 to 18.95$)$ & $<0.001$ & 10.86 (4.88 to 24.2$)$ & $<0.001$ \\
\hline Understanding & 0.69 (0.37 to 1.28$)$ & 0.236 & $0.67(0.35$ to 1.3$)$ & 0.238 \\
\hline Emotional response & 6.99 (3.55 to 13.76$)$ & $<0.001$ & 7.19 (3.46 to 14.99$)$ & $<0.001$ \\
\hline Sense of coherence & $3.99(1.90$ to 8.37$)$ & $<0.001$ & $4.67(2.08$ to 10.5$)$ & $<0.001$ \\
\hline Total IBD-SE & 4.01 (1.89 to 8.49) & $<0.001$ & 4.18 (1.82 to 9.64$)$ & 0.001 \\
\hline
\end{tabular}

${ }^{*}$ Age, gender, type and severity of disease.

tMarital status, working hours, religious belief, severity of disease, the need to take more than three medications, level of income and duration of disease. BIPQ, Brief Illness Perception Questionnaire; IBD-SE, Inflammatory Bowe Disease-Self Efficacy scale.

intervention strategies to optimise these abilities due to their strong connection with the development of anxiety and depression. This will enable the development of new intervention strategies to prevent or allay anxiety and depression.

Allgerante $e t a l^{28}$ proposed a four-part intervention model to improve SE. In their study, an intervention programme was successfully implemented with arthritis patients. Marks et $a l^{26}$ assuming that SE-enhancing interventions can improve SE and influence the patient's affect, created an intervention programme for patients with chronic diseases. They demonstrated that the intervention led to heightened motivation, improved function, better treatment adherence and better clinical and social outcomes. Since our study indicated a strong correlation between SE and patient affect, the intervention model suggested above can improve psychological distress among patients with IBD.

Dorrian $e t \mathrm{al}^{27}$ by using the BIPQ scale in patients with IBD reported that disease activity and pain play a significant part in adjustment. Therefore, they suggested a pain-controlling approach to improve IP among patients with IBD. A study that investigated asthma $^{29}$ found that IP is not influenced by disease characteristics. In our study, we preferred to use the more comprehensive tool of disease severity rather than disease activity. We wanted to investigate whether disease severity over an extended period of 3 years is related to the influence of IP on the patient's affect. The results of the multivariate analysis proved that IP influences anxiety and depression regardless of disease severity. Therefore, intervention programmes to improve IP might improve a patient's affect, regardless of IBD severity.

A small randomised control trial ${ }^{30}$ in patients with myocardial infarction (MI) showed that a three appointments brief in-hospital intervention was successful in changing their perceptions of the MI. Our study raises the importance of using this type of early intervention method for patients with IBD, to prevent progression to depression or anxiety in patients with poor IP.

Feritas $e t \mathrm{al}^{15}$ reported an association of SOC with anxiety and depression, depending on disease duration, among patients with IBD. Our results reinforce

Table 4 Multivariate analysis of psychological parameters influencing depression

\begin{tabular}{|c|c|c|c|c|}
\hline Psychological parameters & Adjusted* OR $(95 \% \mathrm{CI})$ & P value & Adjusted† OR (95\% Cl) & $P$ value \\
\hline BIPQ total & 13.28 (2.86 to 61.68$)$ & 0.001 & $15.8(2.91$ to 86.05$)$ & 0.001 \\
\hline Consequences & 6.95 (2.1 to 23.06$)$ & 0.002 & 11.41 (2.2 to 59.25$)$ & 0.004 \\
\hline Personal control & 6.92 (1.93 to 24.84) & 0.003 & 9.96 (2.07 to 47.97) & 0.004 \\
\hline Treatment control & 2.54 (0.86 to 7.56$)$ & 0.093 & $3.73(0.98$ to 14.19$)$ & 0.054 \\
\hline Identity & $3.48(1.32$ to 9.17$)$ & 0.012 & 4.06 (1.28 to 12.84$)$ & 0.017 \\
\hline Concerns & $6.28(2.03$ to 19.50$)$ & 0.001 & 9.71 (2.42 to 39.02$)$ & 0.001 \\
\hline Understanding & $0.74(0.29$ to 1.90$)$ & 0.535 & $1.03(0.34$ to 3.15$)$ & 0.953 \\
\hline Emotional response & 19.38 (4.3 to 87.41) & $<0.001$ & NA & \\
\hline Sense of coherence & 2.84 (0.93 to 8.64$)$ & 0.066 & 6.12 (1.41 to 25.79$)$ & 0.014 \\
\hline Total IBD-SE & $5.13(1.34$ to 19.22$)$ & 0.015 & 10.99 (1.28 to 94.09$)$ & 0.029 \\
\hline
\end{tabular}

*Age, gender, type of disease and severity of disease.

†Age, gender, type of disease and other variables that were associated with the outcome using backward method (see Statistical methods).

BIPQ, Brief IIIness Perception Questionnaire; IBD-SE, IBD-Self Efficacy scale. 
this association, but the multivariate analysis suggests that the correlation between impaired SOC and depression and anxiety is independent of disease duration. According to Antonovsky's theory, SOC is stable and enduring, indeed, except for one small study in elderly people,$^{31}$ there is still not enough data regarding useful interventions to improve SOC.

The current study had some limitations. First, it included only self-reported measures. So, we cannot refute that an underlying response bias led to our results. Second, the sample was drawn from hospitalbased outpatient clinics only; therefore, it might not be representative of the IBD population. Furthermore, there might be a selection bias that patients who adhere to outpatient clinic visits, have better scores from the beginning or suffer less from anxiety and depression. Third, both patients with Crohn's and UC were included and some studies have recommended caution in applying SOC to different populations. ${ }^{32} 33$

The novelty of our study is that it is the first to address the psychological aspects of IP, SOC and $\mathrm{SE}$ as factors that influence anxiety and depression among patients with IBD. Our results suggest a strong correlation between IP, SOC and SE and the development of emotional distress in patients with IBD. To improve disease management and avoid the progression of anxiety and depression, we advise evaluating IP, SOC and IBD-SE among patients with IBD as early as possible in the treatment process. Early interventions, such as psychotherapy and support groups, may prevent development of anxiety and depression and improve patients' management of the disease. Such interventions should be developed by a multidisciplinary team, including medical psychologists, in order to empower patients with IBD and help them achieve resources to cope with their disease.

\section{Author affiliations \\ ${ }^{1}$ The Kamila Gonczarowski Institute of Gastroenterology and Liver Diseases, Shamir (Assaf Harofeh) Medical Center affiliated to Sackler School of Medicine Tel Aviv University, Zriffin, Israel \\ ${ }^{2}$ Department of Gastroenterology and Hepatology, Meir Medical Center, affiliated to the Sackler School of Medicine, Tel Aviv University, Kfar Saba, Israel ${ }^{3}$ Digestive diseases institute, Shaare Zedek Medical Center, Jerusalem, Jerusalem, Israel \\ ${ }^{4}$ Department of Epidemiology and Preventive Medicine, School of Public, Tel Aviv, Israel}

Contributors AEA, TN, NR, EB performed the research and analysed the data. AEA, TN, NR, EB, ABS, YM, HS, SM, FK, FSB collected the data. TN, NR, EB, designed the study. AEA, NR, TN, EB wrote the paper. AEA, HS, SM, FSB, FK, YM, AS contributed to the design of the study. TZB statistical analysis, wrote parts of the manuscript. All authors approved the final version of the article, including the authorship list.

Funding The authors have not declared a specific grant for this research from any funding agency in the public, commercial or not-for-profit sectors.

Competing interests None declared.

Patient consent for publication Not required.

Ethics approval The study was approved by the committee (Helsinki) of Assaf Harofeh Medical Center, Israel and confirmed on 28 June 2015 . The study protocol conforms to the ethical guidelines of the 1975 Declaration of Helsinki as reflected in a prior approval by the institution's human research committee.

Provenance and peer review Not commissioned; externally peer reviewed.

Data availability statement Data are available upon reasonable request. Data are available upon request.

\section{ORCID iD}

Adi Eindor- Abarbanel http://orcid.org/0000-0001-9677-0453

\section{REFERENCES}

1 Graff LA, Walker JR, Bernstein CN. Depression and anxiety in inflammatory bowel disease: a review of comorbidity and management. Inflamm Bowel Dis 2009;15:1105-18.

2 Fuller-Thomson E, Sulman J. Depression and inflammatory bowel disease: findings from two nationally representative Canadian surveys. Inflamm Bowel Dis 2006;12:697-707.

3 Häuser W, Janke K-H, Klump B, et al. Anxiety and depression in patients with inflammatory bowel disease: comparisons with chronic liver disease patients and the general population. Inflamm Bowel Dis 2011;17:621-32.

4 Filipović B-R, Filipović B-F, Kerkez M, et al. Depression and anxiety levels in therapy-naive patients with inflammatory bowel disease and cancer of the colon. World J Gastroenterol 2007;13:438-43.

5 Jones MP, Wessinger S, Crowell MD. Coping strategies and interpersonal support in patients with irritable bowel syndrome and inflammatory bowel disease. Clin Gastroenterol Hepatol 2006;4:474-81.

6 Walker EA, Gelfand MD, Gelfand AN, et al. The relationship of current psychiatric disorder to functional disability and distress in patients with inflammatory bowel disease. Gen Hosp Psychiatry 1996;18:220-9.

7 Mittermaier C, Dejaco C, Waldhoer T, et al. Impact of depressive mood on relapse in patients with inflammatory bowel disease: a prospective 18-month follow-up study. Psychosom Med 2004;66:79-84.

8 Greenley RN, Hommel KA, Nebel J, et al. A meta-analytic review of the psychosocial adjustment of youth with inflammatory bowel disease. J Pediatr Psychol 2010;35:85769.

9 Panara AJ, Yarur AJ, Rieders B, et al. The incidence and risk factors for developing depression after being diagnosed with inflammatory bowel disease: a cohort study. Aliment Pharmacol Ther 2014;39:802-10.

10 Knowles SR, Wilson JL, Connell WR, et al. Preliminary examination of the relations between disease activity, illness perceptions, coping strategies, and psychological morbidity in Crohn's disease guided by the common sense model of illness. Inflamm Bowel Dis 2011;17:2551-7.

11 Tribbick D, Salzberg M, Connell W, et al. Differences across illness perceptions in inflammatory bowel disease and their relationships to psychological distress and quality of life. Gastroenterol Nurs 2017;40:291-9.

12 Hagger MS, Orbell S. A meta-analytic review of the CommonSense model of illness representations. Psychol Health 2003;18:141-84.

13 Geyer S. Some conceptual considerations on the sense of coherence. Soc Sci Med 1997;44:1771-9.

14 Antonovsky A. Unraveling the mystery of health: how people manage stress and stay well. J Nerv Ment Dis 1987;177:439_ 40.

15 Freitas TH, Andreoulakis E, Alves GS, et al. Associations of sense of coherence with psychological distress and quality of life in inflammatory bowel disease. World J Gastroenterol $2015 ; 21: 6713-27$. 
16 Strecher VJ, DeVellis BM, Becker MH, et al. The role of selfefficacy in achieving health behavior change. Health Educ $Q$ 1986;13:73-92.

17 Keefer L, Kiebles JL, Taft TH. The role of self-efficacy in inflammatory bowel disease management: preliminary validation of a disease-specific measure. Inflamm Bowel Dis 2011;17:614-20.

18 Maeda U, Shen B-J, Schwarz ER, et al. Self-Efficacy mediates the associations of social support and depression with treatment adherence in heart failure patients. Int J Behav Med 2013;20:88-96.

19 Mary JY, Modigliani R. Development and validation of an endoscopic index of the severity for Crohn's disease: a prospective multicentre study. Groupe d'Etudes Thérapeutiques des affections Inflammatoires Du tube Digestif (GETAID). Gut 1989;30:983-9.

20 Leventhal H, Benyamini YBS, et al. Illness representations: theoretical foundations. In: Perceptions of Health and Illness, 1997: 19-45.

21 Sajadinejad MS, Asgari K, Molavi H, et al. Psychological issues in inflammatory bowel disease: an overview. Gastroenterol Res Pract 2012;2012:1-11.

22 Opheim R, Fagermoen MS, Jelsness-Jørgensen L-P, et al. Sense of coherence in patients with inflammatory bowel disease. Gastroenterol Res Pract 2014;2014:1-9.

23 Goodhand JR, Kamperidis N, Sirwan B, et al. Factors associated with thiopurine non-adherence in patients with inflammatory bowel disease. Aliment Pharmacol Ther 2013;38:1097-108.

24 Soares-Filho GLF, Freire RC, Biancha K, et al. Use of the hospital anxiety and depression scale (HADS) in a cardiac emergency room: chest pain unit. Clinics 2009;64:209-14.
25 Zigmond AS, Snaith RP. The hospital anxiety and depression scale. Acta Psychiatr Scand 1983;67:361-70.

26 Marks R, Allegrante JP, Lorig K. A review and synthesis of research evidence for self-efficacy-enhancing interventions for reducing chronic disability: implications for health education practice (Part I). Health Promot Pract 2005;6:3743.

27 Dorrian A, Dempster M, Adair P. Adjustment to inflammatory bowel disease: the relative influence of illness perceptions and coping. Inflamm Bowel Dis 2009;15:47-55.

28 Allegrante JP, Kovar PA, MacKenzie CR, et al. A walking education program for patients with osteoarthritis of the knee: theory and intervention strategies. Health Educ Q 1993;20:63-81.

29 Kaptein AA, Klok T, Moss-Morris R, et al. Illness perceptions: impact on self-management and control in asthma. Curr Opin Allergy Clin Immunol 2010;10:194-9.

30 Petrie KJ, Cameron LD, Ellis CJ, et al. Changing illness perceptions after myocardial infarction: an early intervention randomized controlled trial. Psychosom Med 2002;64:580-6.

31 Kekäläinen T, Kokko K, Sipilä S, et al. Effects of a 9-month resistance training intervention on quality of life, sense of coherence, and depressive symptoms in older adults: randomized controlled trial. Qual Life Res 2018;27:455-65.

32 Karalis I, Langius A, Tsirogianni M, et al. The translationvalidation of the sense of coherence scale into Greek and its use in primary health care. Arch Hell Med 2004;21:195-203.

33 Stein JA, Lee JW, Jones PS. Assessing cross-cultural differences through use of multiple-group invariance analyses. J Pers Assess 2006;87:249-58. 